\title{
Challenges of Blood Transfusion in a Developing Country and the Ways Forward
}

\author{
Ogbonna Collins Nwabuko*1-3 and Thomas Obiora Nnaji ${ }^{4}$ \\ ${ }^{1}$ Department of Haematology and Blood Transfusion, Federal Medical Centre, Umuahia, Abia State, Nigeria \\ ${ }^{2}$ Department of Haematology, College of Health Science, Abia State University, Aba Campus, Abia State, Nigeria \\ ${ }^{3}$ Department of Public Health Sciences, Walden University, Baltimore, USA \\ ${ }^{4}$ Department of Internal Medicine, Alex Ekwueme Federal University Teaching Hospital, Abakiliki, Ebonyi State, Nigeria \\ *Corresponding author: Ogbonna Collins Nwabuko, Department of Haematology, Federal Medical Center, Aba Road, PMB 7001, \\ Umuahia, Abia State, Nigeria
}

\section{ARTICLE INFO}

Received: 幽 January 23, 2021

Published: 幽 February 04, 2021

Citation: Ogbonna Collins Nwabuko, Thomas Obiora Nnaji. Challenges of Blood Transfusion in a Developing Country and the Ways Forward. Biomed J Sci \& Tech Res 33(4)-2021. BJSTR. MS.ID.005435.

Keywords: Blood transfusion; Challenges; SWOT Analysis; VNRBD; Developing Country; Nigeria

\section{ABSTRACT}

Unsafe BT is a major public health problem in sub-Saharan Africa due to high patronage on commercial blood donation as against the WHO recommended voluntary non-remunerated blood donation. According to WHO blood safety report in Africa, 250500 people are infected with HIV daily as a result of unsafe blood transfusion. Unsafe blood transfusion practice is a major contributor to morbidity and mortality in a developing country such as Nigeria. This review study gives insight into the challenges of BT in Nigeria and the strategic leadership approaches to attain blood safety and curb the morbidity and mortality attributable to unsafe BT practices in the region.

Abbreviations: ABO: A, B, AB, O blood group system; Alb: Albumin Solution; ARCBS: Australian Red Cross Blood Service; BB: Blood Bank Center; BPs: Blood Products; BT: Blood Transfusion; BTP: Blood Transfusion Practice; BTR: Blood Transfusion Reaction; CD: Commercial Donation; CDC: Center for Disease and Protection; CBT: Component Blood Transfusion/Therapy; EBT: Exchange Blood Transfusion; FRD: Family/Friend Replacement Donation; FFP: Fresh Frozen Plasma; HBV: Hepatitis B Virus; HCV: Hepatitis C Virus; HICs: High-Income Countries; HIV: Human Immunodeficiency Virus; HTLV-1/2: Human T-cell Lymphotrophic Virus sub-type 1 and 2; LICs: Low-Income Countries; pdFVIII: plasma-derived clotting factor VIII; IgIV or IgSC: Polyvalent human Immunoglobin; QOL: Quality of Life; RCE: Red Cell Exchange Transfusion; SBTS: Standard Blood Transfusion Service; TM: Transfusion Medicine; TT: Transfusion Transmissible; TTIs: Transfusion Transmissible Infectious Diseases; VBD: Voluntary Blood Donation; VNRBD: Voluntary Non-remunerated Blood Donation; WNV: West Nile Virus; WB: Whole Blood; WBC: White Blood Concentrate; WBT: Whole Blood Transfusion; WBDD: World Blood Donors Day; WHA: World Health Assembly; WHO: World Health Organization

\section{Short Communication}

Blood is a vital component of human body with magical quality. It cannot be manufactured artificially but can be donated from a healthy person. It is a prime tool in medicine tagged "the gift of life." Blood is perceived as dynamite - it could be life-saving when safe, but life-threatening if unsafe [1] It is an important resource for planned and urgent medical and surgical interventions. Its importance gave birth to WBDD celebrated globally on $14^{\text {th }}$ June every year [2]. Every year, on the 14 June, countries around the world celebrate the WBDD. The WBDD serves three purposes and these include: to raise awareness of the need for blood and BPs; appreciation of donors for the life-saving gift (blood), and advocacy on the need for sustainability of safe blood donation. Blood transfusion is the process of collection and infusion of blood or BPs from human (donor)-human (recipient) [3]. BT is an important arm of transfusion medicine of public health relevance. It is a prototype of organ transplantation. There are two major types of BT namely the allogeneic or homologous and syngeneic or autologous BT. The two major methods of BTP include: the simple transfusion (also known as WBT or Top-up transfusion) and CBT (also known as EBT). Technically speaking, the WBT method is an old-fashioned, 
crude, unsafe manual (analogue) mode of administering blood while the CBT is the current, safer automated (digital) method of blood administration. It is actually the CBT that qualifies blood as a gift of life. Blood can only be a gift for life when it is safe for transfusion.
The components derivable from blood include red cell concentrates, WBC or Granulocyte concentrates, Platelet concentrates, FFP (recovered from WB or sourced by Apheresis), pd-FVIII, IgIV or Ig SC, Alb, cryoprecipitates , and other cryosupernatants (Table 1)[4].

Table 1: The major BPs produced by ARCBS and their clinical indications, storage conditions, average volume and method of production [4].

\begin{tabular}{|c|c|c|c|c|c|}
\hline Serial Number & BPs & Indications & Storage Condition & Volume (ml) & Production method \\
\hline 1 & $\begin{array}{l}\text { Un-refrigerated whole } \\
\text { blood, } \\
\text { leukocyte-depleted }\end{array}$ & Limited uses, shock & $24 \mathrm{~h}$ at $20-24^{\circ} \mathrm{C}$ & $450 \pm 10 \%$ & WB derived \\
\hline 2 & Red Cell Concentrate & Anemia, Blood loss & 42 days at $2-6^{\circ} \mathrm{C}$ & $>240$ & Typically WB derived \\
\hline 3 & Platelet Concentrate & $\begin{array}{l}\text { Bleeding due to platelet deficiency, } \\
\text { decreased platelet production, or } \\
\text { decreased platelet function }\end{array}$ & 5 days at $20-24{ }^{\circ} \mathrm{C}$ & $\begin{array}{l}100-400 \\
\text { (Apheresis) }>160 \\
\text { (Buffy Coat) }\end{array}$ & $\begin{array}{l}\text { Apheresis or Buffy } \\
\text { Coat method }\end{array}$ \\
\hline 4 & Fresh Frozen Plasma & $\begin{array}{l}\text { Coagulopathy where the specific } \\
\text { factor is not available. Replacement } \\
\text { of specific plasma protein. }\end{array}$ & 12 months at $\leq-25^{\circ} \mathrm{C}$ & $\begin{array}{c}250-334 \text { (can range } \\
\text { up to } 750 \text { ) }\end{array}$ & $\begin{array}{l}\text { Apheresis or WB } \\
\text { separation }\end{array}$ \\
\hline 5 & Cryodepleted plasma & $\begin{array}{c}\text { Plasma exchange, particularly for } \\
\text { TTP }\end{array}$ & 12 months at $\leq-25^{\circ} \mathrm{C}$ & $255 \pm 10 \%$ & $\begin{array}{l}\text { Apheresis or WB } \\
\text { separation }\end{array}$ \\
\hline 6 & Cryoprecipitate & Fibrinogen deficiency & 12 months at $\leq-25^{\circ} \mathrm{C}$ & $30-40$ & $\begin{array}{l}\text { Apheresis or WB } \\
\text { separation }\end{array}$ \\
\hline
\end{tabular}

A safe Blood is blood voluntarily (non-remunerated) donated by a healthy adult (18-60 years) donor without risk to his health, and the donor meets the health and screening criteria without transmitting TT diseases or causing other adverse effects such as BTR to the recipient. The indicators of "safety" in blood for transfusion are the mode of donation (whether it is paid or unpaid); health status of the donor; age of the donor and risk status (for donor and recipient). SBTS, therefore, encompasses blood donor clinic, voluntary blood donor pool, screening of donors' blood, blood banking, and provision of safe blood (Figure 1). A SBTS center must establish measures to protect the donor and recipient before it is certified as a carrying out safe BTP. The standard operating procedures for processing a blood in order to attain safety occur in the BB. The BB is a place where blood collection (donation), screening (i.e., infectious diseases and compatibility testing) and storage are carried out. Prospective donors are screened for possible TTIs (such as HIV, HBV, HCV, Syphilis, HTLV-1/2, CMV, Parvovirus, Malaria, WNV, Trypanosomiasis, and others) in the BB. The facilities for autologous blood, apart from homologous (allogeneic) blood are found in the BB. A modern BB provides facilities such as apheresis machines for RCE, plasmapheresis, cytapheresis, coagulation disorders, just to mention a few. An ideal BB must have a receiving, testing, storage and distribution units. Between these four major units there must be a preparatory and ordering units. The patient and donor specimen are received in the "receiving unit" while the BPs come into BB through the receiving unit and move out via the distribution unit (Figure 1). There are two major goals SBTP strives to achieve in TM. The first one is to ensure the safety of the donor while the second one is to ensure the safety of recipient. There are three measures adopted to maintain safety of the donor (what may be termed inclusion and exclusion criteria for prospective blood donors). They include: hemoglobin estimation (13.5g/dL in Male; $12.5 \mathrm{~g} / \mathrm{dL}$ in Females); volume of blood donated at a given time and donation interval: (3-4 times per annum). In addition, there are four measures adopted to ensure safety of the recipient (otherwise known as the donor-selection criterion) include:

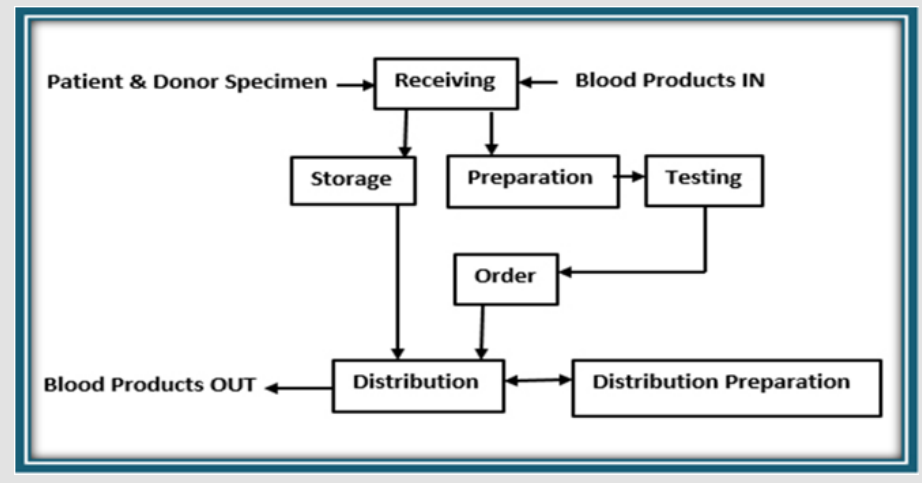

Figure 1: An ideal BB infrastructure (Block Concept) showing the various units of blood flow. 
1) ABO-Rh blood grouping and cross-matching before transfusion. Group-specific blood transfusion is the topmost priority of SBT in this criterion.

2) Screening test: Donor blood is subjected to screening tests against infectious agents.

3) Blood Storage: the suitability of anticoagulant-containing blood container is a vital component of SBTP.

4) Tests to handle complications of BTR (Rhesus-ABO antibodies test) as in ABO-Rh or inter-donor incompatibilities.

In Safe BTP, CBT is the rule- only deficient blood component in a recipient is replaced with the donor's blood. This mechanism saves blood wastage as one unit of blood can provide several BPs. Safe BT is a palliative intervention as it can improve the QOL of the severely anemic dying patient.In order to sustain Safe BTP, VNRBD pool is recognized globally as the safest source of blood. The WHO recognized VNRBD as the foundation for safe, sustainable, sufficient and secured blood [5-6]. The sustainability of safe blood self-sufficiency via VNRBD can be achieved by the implementation of the WHO recommendations. This recommendation forms part of the SDG-3 agenda [7]. These WHO recommendations also known as the WHO resolution on safe blood are enshrined in WHA.

1) WHA 28.72 (1975): Utilization and supply of human blood and blood products [8]

2) WHA 56.30 (2003): Global health-sector strategy for HIV/AIDS [9]

3) WHA 58.13 (2005): Blood safety: proposal to establish WBDD [2]

4) WHA 63.12 (2010): Availability, safety and quality of blood products [10]

5) Melbourne Declaration of 100\% VNRBD (June 2009) [11]

6) WHO Global Blood Safety Network [12]

These WHA resolutions are needed in order to ensure security, safety and sufficiency of blood to all patients.

\section{Epidemiology}

The WHO recommends blood donation by $1 \%$ of any given population as the minimum requirement needed to meet the nation's most basic needs in order to ensure sustainable sufficiency in safe blood. About 112.5 million blood donations of blood are collected globally annually out of which $50 \%$ occur in HICs of the world. About 57 countries have achieved 100\% in VNRBD. The average blood donation in LICs is fifteen times lower than their HICs counterparts as in 2006 [13]. Globally, more than seventy countries have a blood donation rate $<1 \%$ (10 per 1000 persons). In Africa only 40\% (3.2 million as against 8.0 million) of the minimum requirement of BD was met in 2006. In Nigeria, 33.3\% ( 0.5 million as against 1.5 million) of the minimum requirement of blood was met in 2006 [14]. The 3 Forms of Blood Donation according to definitions on blood safety endorsed by WHO Expert Groups include: VNRBD -( altruistic giving, non-remunerated, for life-saving);Family/Friend Replacement Donation (FRD), which is a donation on goodwill, to save cost and Commercial (Paid) Donation (CD)- which is majorly for financial gratification [15]. In Nigeria public healthcare sectors, $75 \%$ of blood donations are FRD while $25 \%$ are sourced commercially. The reverse is the case in private sectors where CD (75\%) is the major source of blood donation while $25 \%$ are contributed by FRD. The VNRBD contribution to blood pool in Nigeria is negligible [14].

\section{SWOT Analysis of BT in Nigeria}

The acronym 'SWOT' connotes Strengths, Weaknesses, Opportunities, and Threats. The hindrances to conducting successful safe BTP in Nigeria are the challenges. These challenges are categorized under the weaknesses and threats to safe BTP in Nigeria. The challenges include

\section{Lack of Enabling Environment for VNRBD such as :}

i. Poor health promotion- no strong advocacy for $100 \%$ VNRBD.

ii. Failure to establish a VBD program.

iii. Poor legislation (policy) on Safe BTP.

iv. Poor funding.

v. Poor infrastructures: an ideal hospital transfusion service workflow status is still a far cry.

vi. Lack of modern facilities for CBT - no apheresis or cold centrifuge machine.

vii. Lack of adequate manpower - specialist staff with marketing and communication skills for education and motivation.

viii. Poor documentation- No database and Information management system.

ix. Poor quality control system.

x. No emergency preparedness response plan.

Challenges due to choice of Blood Donation: The CD and FRD are predominant sources of blood in Nigeria as against VNRBD which is predominant in developed countries. CD is illegal, lacks documentation and predisposed to TTI $[1,3,14,16]$.

Challenges due to High Prevalence of TTIs: The high prevalence of TTIs in the general/donor population is a strong set-back to achieving SBT. This is not usually the case with routine VNRBD.

Blood Supply Deficit: There is a need to invest more money in transfusion medicine in LICs to achieve the minimum requirement of sustainability, security, safety and sufficiency in blood transfusion. The NBTS (established in 2005) in Nigeria is moribund due to poor 
funding and leadership failure. This accounts for the gross supply deficit in the NBTS centre ( $<4 \%$ eligible donors donate blood).

Blood Storage Deficit: Prolong blood storage: routine cold storage of blood in BB leads to deterioration of red blood cell quality, a condition leading to storage-induced damage to red cell membranes. This can lead to pulmonary hypertension, venous thromboembolism, and Transfusion-Related Acute Lung Inflammation [4].

\section{Donor Unit Processing:}

a. Mismatch of ABO-Rhesus Blood Groups: Transfusion medicine is a crucial arm of Forensic pathology. It can be used to determine the origin of the peoples that make up a population. In condition where the blood is not accurately typed before transfusion, this could lead to adverse blood reaction - BTR.

b. Screening for TTIs: Although the double ELISA and NATs are the standard techniques for screening the major TTIs (HIV, HCV, HBV and Syphilis). However, they are not readily accessible.

c. Blood Transfusion Reactions: BTR is one of the adverse effect of mis-match of ABO-Rhesus blood group. This can be immediate or delayed, immune-mediated and non-immune mediated in origin (Figure 2).

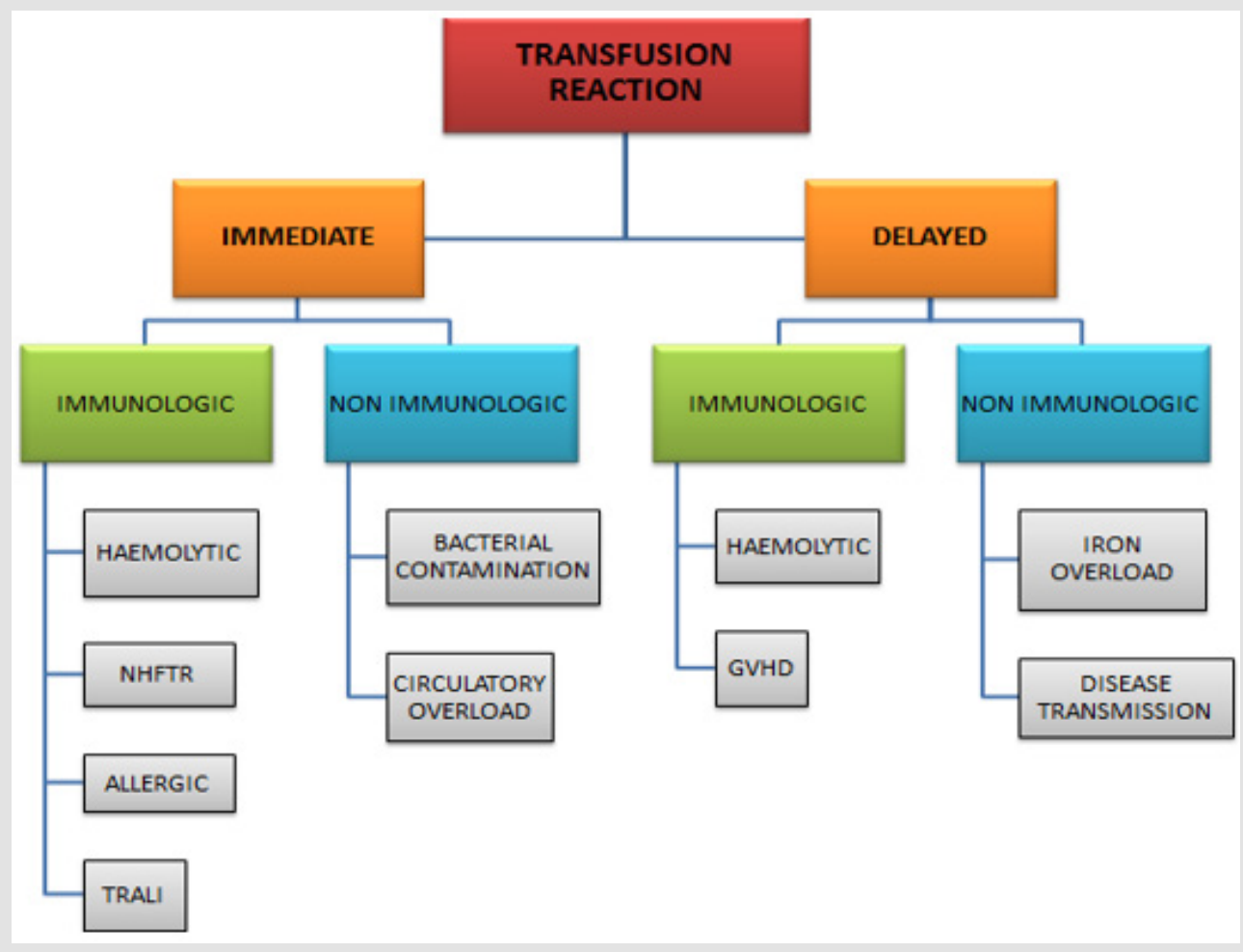

Figure 2: BTR showing the various types.

The current global framework on SBT is geared towards $100 \%$ VNRBD. This framework has four goals and twenty strategies viz:

1) Goal A: Create Enabling Environment for VNRBD - This goal has 3 strategies for its implementation.

2) Goal B: Foster culture of VBD - This goal has 7 strategies for its implementation.

3) Goal C: Build and maintain safe sustainable VBD Base This goal has 6 strategies for its implementation.

4) Goal D: Provide Quality Donor Services and Care - This goal has 5 strategies for its implementation.

In addition to the above framework, other strategic approaches to improve the scorecard of SBT in a developing country such as Nigeria are to:
1) Revive the NBTS: There is a need to revive the NBTS through funding and legislative backing to become fully recognized institution.

2) Embark on VNR Blood Drive: Did I hear "One million safe blood unit initiative" by the NBTS national co-ordinator?

3) Improve leadership style-(Government Commitment): Good health governance from top-down.

4) Partner/Collaborate with supportive agencies: such as Donor agencies, Philanthropists, NGOs, multi-lateral health organizations such as WHO, CDC, United Nations, Rotary Club, Red Cross Society National Institute of Health just to mention a few for funding on research in TM.

5) Safe Blood Transfusion- COVID-19 Era: There is a need for emergency response readiness in the COVID-19 era as 
regards to sustainability of safe Blood. Efforts must be made to enhance donor safety through social distancing, infection control (hand hygiene, temperature check and use of face mask). Ensure staff health and safety by implementing CDC guidelines on COVID-19 for blood and plasma collection [17].

\section{Conclusion}

Unsafe BT is a major public health challenge in a developing country such as Nigeria. I think it is time to change the narrative. It is time to change the crude unsafe choice of CD to safe VNRBD. It is time to change the age-long simple (whole blood) method of blood transfusion to the current CBT. It is time to re-structure our infrastructures in TM. This will be in the interest of our current and future generations. It will also be in the interest of accountability, transparency, and high evidence-based research studies in transfusion and forensic medicine.

\section{Acknowledgement}

I wish to acknowledge Professor. O.A. Ejele, for his mentorship and expertise in hematology; Professor. Ann Merrimen, for her expertise in Palliative Medicine and all my research colleagues for their inspiration in academic writing.

\section{References}

1. Nwokeukwu IH, Nwabuko OC, Chukwu A, Ajuogu E, Okoh AD (2015) Prevalence of human immunodeficiency virus, hepatitis B virus, hepatitis $C$ virus, and Syphilis in blood donors in a tertiary health facility in south eastern Nigeria. Hematol Leuk 2: 4.

2. WHO (2017) World Blood Donor Day: archive.

3. Nwabuko OC, Nnoli MA, Okoh AD, Chukwuonye II (1970) Taming the tide of HIV, TTI scourge in sub-Saharan Africa using autologous blood transfusion. Hematol Leuk 1: 7.

\section{ISSN: 2574-1241}

DOI: $10.26717 /$ BJSTR.2021.33.005435

Ogbonna Collins Nwabuko. Biomed J Sci \& Tech Res

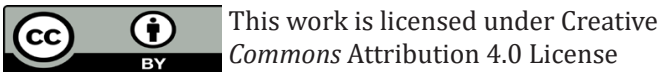

Submission Link: https://biomedres.us/submit-manuscript.php
4. Greenings DW, Glenister KM, Sparrow RL, Simpson RJ (2009) International blood collection and storage: clinical use of Blood Products. J of Proteomics 73(3): 387-395.

5. Leikola J (1998) Achieving self-sufficiency in blood across Europe. British Medical Journal 316 (7130): 480-490.

6. WHO (2012) Expert Group. Expert Consensus Statement on achieving self-sufficiency in safe blood and blood products, based on voluntary non-remunerated blood donation (VNRBD). Vox Sang 103(4): 337-442.

7. WHO (2009) The Melbourne Declaration on $100 \%$ voluntary nonremunerated donation of blood and blood components. Geneva, Switzerland.

8. WHO (1975) Twenty-Eighth World Health Assembly. Geneva, Switzerland.

9. WHO (2007) Global Health-Sectorstrategy for HIV/Aids? p. 3-34.

10. WHO (2010) The World Health Assembly Resolution on availability, Resolution on availability, safety and quality of blood safety and quality of blood products? P.1-13.

11. WHO (2016) Reaching young blood donors.

12. WHO (2011) Global Blood Safety Network.

13. WHO (2009) WHO blood safety indicators 2007.

14. Aneke JC, Okocha (2017) Blood transfusion safety; current status and challenges in Nigeria. Asian J Transfusion Sc 11(1): 1-5.

15. WHO (2012) WHO Expert Group. Expert Consensus Statement on achieving self-sufficiency in safe blood and blood products, based on voluntary non-remunerated blood donation (VNRBD). Vox Sang 103(4): 337-342.

16. Eastlund T (1998) Monetary blood donation incentives and the risk of transfusion-transmitted infection. Transfusion 38(9): 874-882.

17. Nwabuko 0, Nnaji OT (2020) Epidemiology in the news- the case of COVID-19 pandemic disease. IOSR-JDMS 19(5): 35-38.

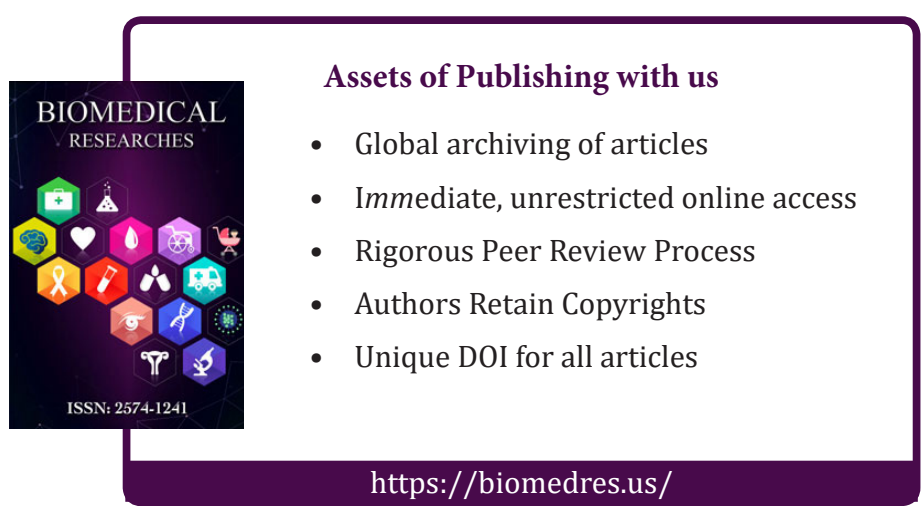

